\title{
Analysis on Design Principles of Public Facilities on Campus and Its Adaptability to Campus Environment
}

\author{
Xiling Han \\ School of Fine Arts \\ Huanggang Normal College \\ Huanggang, China
}

\author{
Hai Cheng \\ School of Fine Arts \\ Huanggang Normal College \\ Huanggang, China
}

\begin{abstract}
Colleges are training base of high quality talents and the place for students to learn and communicate. Public facilities on campus are essential. In-depth investigation has been made on public facilities on campus of Huanggang Normal College. According to the contrastive analysis on problems in it and the analysis of causes, we should arouse students' enthusiasm in design and construction of public facilities on campus and make them establish a sense of ownership, in order to train their overall quality, assimilate connotation of personality and create harmonious campus with the atmosphere of humanism.
\end{abstract}

Keywords - campus environment; dustbin; design principle

\section{CURRENT Situation OF PUblic Facilities ON CAMPUS}

Large-scale city construction is underway. The design of urban public construction is valued increasingly, including the landscape design on college campus. The rapid development of college construction exposes some contradictions between public facilities and education. It requires us to do innovative design on public facilities on campus.

Public facilities on college campus mainly include teaching infrastructure, sanitary facilities, transport facilities, rest facilities and recreational facilities. College campus is the cultural core of a city with long historical context. Colleges neglect the expression of campus context and humanized design and lack reasonable overall planning of public facilities on campus. Public facilities on campus are frequently used and some are damaged seriously. Colleges need to establish sound maintenance mechanism to guarantee the beautiful landscape on campus.

According to field survey, comprehensive research, analysis and summary of current situation of campus in Huanggang Normal College, it finds the public facilities have many problems: value function and neglect ornamental value; lack integrated planning and context connotation; single modeling and inadequate number, unreasonable distribution location; facilities are damaged seriously and not maintained timely.

Project source: Huanggang Normal College 2016 experimental teaching demonstration center college student innovation activity project (No.: zX201603).

\section{DESIGN PRINCIPLE OF PUblic FACILITIES ON CAMPUS}

As the invisible education carrier of college culture, public facilities on campus differ from urban public facilities and the design principles are also different. Except for the basic functional design principle, public facilities on campus have various design principles like cultural principle, systematic principle, and principle of environment coordination, principle of sustainable development and principle of valuing public participation.

\section{A. Cultural Principle}

At the initial stage, in order to serve the society and meet the demands of users, campus construction values function and neglect landscape design and cultural expression, causing reasonable factors and reducing the usage rate of public facilities. Colleges have teaching idea, campus spirit and value orientation in the long history and gradually form characteristic teaching style and spiritual culture. The design of public facilities on campus needs to embody the cultural features and extract characteristic culture symbols to carry out innovative design, in order to coordinate public facilities on campus with humanistic environment. According to observation and research on students' behavior and psychological features, colleges improve use function and innovate in external image of public facilities, in order to design safe, beautiful, comfortable and regional, humanized public facilities to serve students. Huanggang Normal College has a history of 110 years. Brave advancement and ceaseless self-improvement is the formulation of the school's mission and the spiritual qualities of people in this college. Profound cultural deposits are integrated with public facilities on campus to form campus with rich culture and local features. Longplaying campus life contributes to the formation of thoughts and emotions and values, inheritance of cultural connotation on campus and improvement of material culture, influencing numerous students from generation to generation. The design of public facilities on campus should first value the cultural principle.

\section{B. Systematic Principle}

Campus is the main place for activities and communication. Public facilities are frequently used and suffer from different levels of damages. Without timely maintenance, it directly influences the landscape of school. Household garbage stacks 
increasingly and brings burden for people in garbage collection. Cleaning, repair and maintenance of public facilities need systematic management to solve problems like many sudden faults, few planned maintenance, and backward and formalistic management system. Besides, colleges should formulate systematic management policy and let administrative departments have clear division of work. Responsible persons should manage public facilities and prevent lose and damage, overstock and waste of it. Establish the idea focusing on the service for teachers and students, improve the service efficiency of educational resources, strengthen the management of public facilities and build sound rules and regulations to protect public facilities and serve teachers and students. Systematic principle is the key to design of public facilities on campus.

\section{Principle of Environment Coordination}

With use function, public facilities on campus highlight landscape characteristics and become the finishing touch of campus environment. Different from single product design, it is not isolated from the environment but strengthen the appealing force of environment. [2] The design modeling of public facilities is unified. Many problems appear in construction planning and use. It fails to create the atmosphere in school and lacks systematic development idea. Designers should respect differences, innovate in forms and arrange reasonably. Space and materials, image and color of public facilities coordinate with the environment. According to the environment and function division of college campus, the design and reconstruction of public facilities must comply with humanistic spirit and artistic connotation, value coordination and overall effect to avoid chaotic landscape and unbalanced environment coordination and crate harmonious campus environment. [3] The principle of environment coordination is the key point in design of public facilities on campus.

\section{Principle of Sustainable Development}

With the reinforcement of consciousness in protection of resources and environment, new theories, technologies and design ideas relevant to resource protection are proposed and implemented unceasingly. [4] Designers of public facilities seek alternative materials or forms of non-renewable resources from the perspectives of economic and environment-friendly principle, promote the application of clean energy and energysaving device and advocate the activity of going green and environmental protection. Water saving instruments can be used in residential buildings and public buildings on campus. Rainwater can be collected, regulated and stored in underground pool to green the campus and clean the road. The energy consumption of lighting electrical appliances and office electronics is big. Colleges can use photovoltaic panels in available space, combine natural lighting and auxiliary artificial lighting, use energy-saving electric appliance and carry out time-sharing control and zone control of lighting systems in every floor. The principle of sustainable development is characteristic in design of public facilities on campus.

\section{E. Principle of Valuing Public Participation}

User experience expert Nathan Shedroff once addressed, experience refers to the activity that designers integrate the participation of users in design and make them have comfortable feelings and create valuable memories through service, products and environment. [5] Students in contemporary era lose the environmental awareness and have confusing idea of garbage classification. The design and construction of public facilities fail to collect the public opinions so that it cannot meet students' daily demands and reduces the usage rate of public facilities. College students have strong ability of independent thinking and have personal experience of public facilities on campus. Schools should arouse students' enthusiasm to design and construct public facilities on campus, take their advice and meet their demands in using public facilities. The principle of public participation is the guarantee for design of public facilities on campus.

\section{RESEARCH OVER VIEW WITH DUSTBINS OF HuAngGang Normal College as An ExAmple}

Public facilities are bridge between human and nature, helping people to dialogue with nature more directly and conveniently and coordinating the relationship between people and campus environment. Excellent design of public facilities effectively improves frequency of utilization and saves energy indirectly. Meanwhile, it makes teachers and students participate in protection of public facilities and campus environment, strengthening their sense of ownership and belonging. [6]

Dustbins are important sanitary facility on campus. It should be functional, have adequate capacity and classify garbage, easy for people to use and clean. Concise and vivid design idea runs through the whole design to embody the convenient style of product from materials, functions and innovative modeling. Dustbins have functions of two levels. The first is basic functions like receive, hold and dump garbage; the second is auxiliary functions like keep out wind and rain and prevent the garbage from scattering in all directions; fixed position and reasonable layout; beautiful and utility with strong functions, integrate with the environment; convenient to move and dump garbage. "Fig.1"

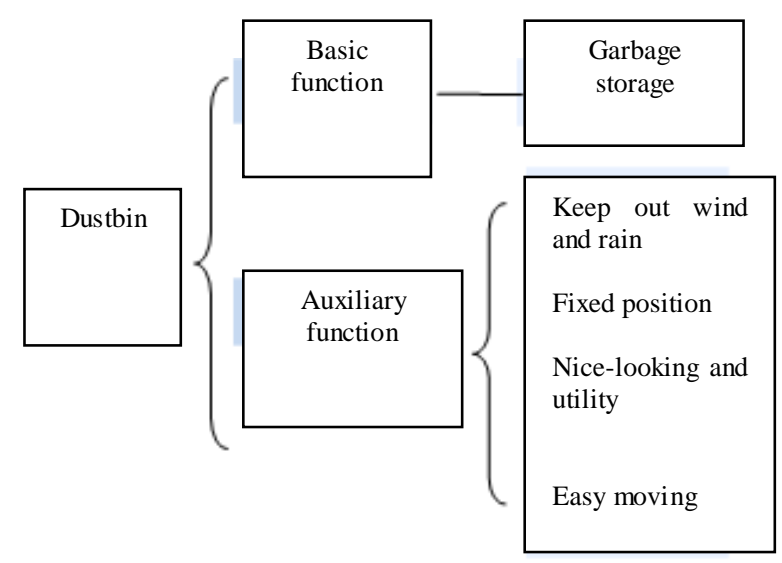

Fig. 1. Functional system of dustbin. 
Works wining the utility and excellent prize in "CNature Happiness and Color Uprising_Environment-friendly Dustbin Design Competition" are applicable to campus. The design description: The dustbin has concise appearance with the modeling that two people hug each other with soft lines. It passes the idea of mutual help, strengthens students' awareness in protection of public facilities and promotes the creation of campus landscape with aesthetic education. The outer contour uses stainless steel and renewable materials. It advocates garbage classification and publicizes environmental protection concept and strengthens students' sense of belonging and participation. The public environment on campus also needs the protection of students. "Fig. 2"

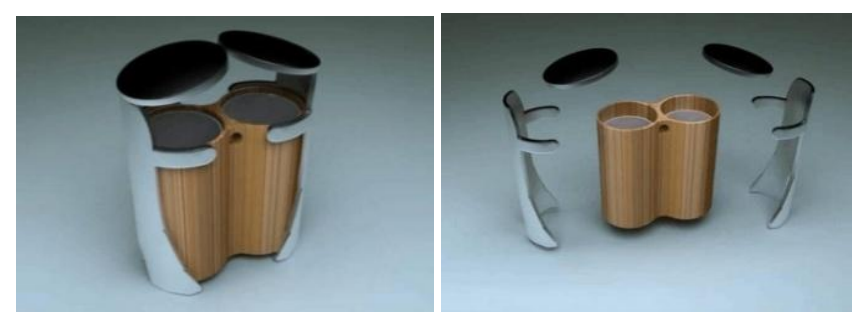

Fig. 2. The design of dustin.

\section{CONCLUSION}

Public facilities are detailed expression of a place. Excellent design of public facilities is the sublimation from function to spirit. Public facilities should be functional and foil landscape. Designers of public facilities consider cultural characteristics and extract culture symbols with regional characteristics. It is the spirit carrier of a place. Demands decide design. In design of public facilities on campus, students' opinions should be valued to make campus life more convenient and comfortable and safer. According to the research on campus, many public facilities need improvement through careful observation, in order to construct a beautiful and cozy campus and provide referential significance for the construction of public facilities on campus in the future.

\section{REFERENCES}

[1] Xie Tianshi, Yu Dongming, Man Xiuyun. Research on Construction of Public Facilities in Universities-Take New Campus of Shangdong Agricultural University as an Example [D], China Agricultural Science Bulletin, 2013.(29)20:210-213

[2] Ni Lei. Discussion on Design of Public Facility in University Campus [D], Journal of Shandong Agricultural Engineering College, 2014.31(6): 46-47

[3] Li Wenjia, Ren Mei, Kong Xiaoyan. Research on Design and Construction of Public Facilities under the Perspective of City Landscape, Packaging Engineering, 2013.34(2): 57-60

[4] Wang Yong, Yu Jinlei, Su Buqing. Research on Experience Design of Public Facilities in Mathematics Garden, Packaging Engineering, 2015.(36)6: 88-91

[5] Miao Guangna. Discussion on Energy Conservation Design of Public Facilities in Universities under Product Guide, Ecological Economy, 2015.31(7):181-184 